\title{
Formation and Development of Chinatown in Japan:
} Chinatowns as Tourist Spots in Yokohama, Kobe and Nagasaki

\author{
YAMASHITA Kiyomi \\ Faculty of Regional Development Studies, Toyo University, Gunma 374-0193, Japan
}

\begin{abstract}
In Japan, so-called Chinatowns have been formed only in three cities of Yokohama, Kobe and Nagasaki, and are named respectively Yokohama Chinatown, Kobe Chinatown, and Nagasaki Chinatown. Based on the author's previous studies and fieldwork, this paper aims to clarify the regional characteristics of Chinatowns in Japan. Every Chinatown in Japan exists as a very important tourist spot with highly concentrated Chinese restaurants of various sorts. From the global point of view, this appears to be the most remarkable regional characteristic of Chinatowns in Japan. Compared with those in Southeast Asia, Europe and North America, Japanese customers and tourists play a more important role than the ethnic Chinese in the functions of Chinatowns in Japan. This remarkable characteristic would be that the ethnic Chinese in Japan have been trying to adapt themselves to the Japanese community by promoting Chinatowns as tourist spots. They have been positively utilizing the tradition of Chinese culture, especially food culture, as a tourist resource. Chinatown in Japan is a town that embodies the image of China, cherished by so many Japanese. This is based upon the historical interest in Chinese culture among the Japanese people.
\end{abstract}

Key words: ethnic Chinese, Chinatown, Japan, Yokohama, Kobe, Nagasaki

\section{Introduction}

In recent years, the study on Chinese communities in Japan is flourishing and is approached from various viewpoints: history, economics, sociology, cultural anthropology, literature and so on. In geography, the prevailing feature of study on Chinese communities could be that it emphasizes the space aspect (e.g., distribution and residential pattern of ethnic Chinese) and landscape aspect. Another feature of geographic study on Chinese communities would be that it interprets the local and universal characteristics of Chinese communities and inquires into the cause of such characteristics as well. The book by Ma and Cartier (2003) is highly evaluated as the first book to explore ethnic Chinese communities all over the world from geographical perspectives.

I have been consistently studying Chinese communities in Japan and overseas, from the geographic point of view. I started with a study on Yokohama Chinatown (Yamashita 1979), and then expanded study areas to Kobe and Nagasaki. While studying the Three Big China- towns in Japan, I had an opportunity to study at Nanyang University in Singapore and started comparative studies on Chinatowns in Southeast Asia (Yamashita 1986, 1987a, 1987b, 1988, 2002). Moreover, I worked at University of California, Berkeley, as an overseas researcher of the Japanese Ministry of Education. While collecting references, I endeavored to understand the actual condition of most of the Chinatowns in the U.S. Since then, I have conducted field studies on Chinatowns all over the world including Canada, Australia, and Europe, focusing on land utilization and landscape.

Among the studies on Chinatown by geographers, studies on Chinatowns in Boston by Murphey (1952), in Victoria, Canada by Lai (1988) and in Vancouver by Anderson (1991) are most noteworthy. Murphey argued formation of Boston's Chinatown from the view point of sequent occupance. Lai discussed Victoria's Chinatown as a typical example of an "Historic Chinatown," and described a public involvement model of community planning of Chinatowns. Anderson argued that "Chinatown" is a Western construction, and pointed out that the 
district of "Chinatown" is defined and shaped according to Western images and interests. These studies gave me ideas and suggestions for considering of the development of Chinatowns in Japan.

Chinatown is a commercial and business area with a concentration of ethnic Chinese population, developing in the context of their own Chinese culture with respective local cultures from where they immigrated. As each Chinatown reflects faithfully how ethnic Chinese have adapted themselves to the local community, it has characteristics specific to each residing area. I have summarized my previous studies (Yamashita 2000) based on comparison of many Chinatowns in the world from the global standpoint.

In this study, I focused on Chinatowns in Japan. So-called Chinatowns have been formed only in Yokohama, Kobe and Nagasaki, and are named respectively Yokohama Chinatown, Kobe Chinatown, and Naga-saki Chinatown. Based on the author's previous studies and fieldwork, this paper aims to clarify the regional characteristics of Chinatowns in Japan from the global standpoint.

\section{Ethnic Chinese in Japan and the Three Big Chinatowns}

According to the "Statistics of Foreign Nationals in Japan 2003" by the Ministry of Justice, there were as many as $1,851,758$ residents of foreign nationalities in Japan at the end of 2002 , corresponding to $1.45 \%$ of aggregate population in Japan. This indicates that multinationalization of the Japanese community is consistently progressing. Among the nationalities, Korean nationals are the most numerous $(625,422$ residents, $33.8 \%$ of all foreign nationals), and Chinese nationals are the second most (424,282 residents, $22.9 \%$ ). While this number includes many students from Mainland China, whose number has increased sharply in the 1980 s, those who have already been naturalized as Japanese nationals are excluded.

Although many might think that the Japanese prefecture with the largest population of Chinese nationals is Kanagawa Prefecture, where Yokohama Chinatown is located, this is not true. The correct answer is Tokyo Metropolitan Prefecture, where 26.4\% $(112,208)$ of Chinese nationals in Japan reside. However, an area that can be called explicitly "Chinatown" has never been formed in Tokyo. Within Japan, Chinatowns have been formed in three cities (i.e. Yokohama, Kobe and Nagasaki) and are named respectively Yokohama Chinatown [YOkohama Chukagai 横浜中華街] (Yamashitacho, Naka Ward, Yokohama City), Kobe Chinatown [Kobe Nankinmachi 神戸南京町] (1-chome and 2-chome each of Motomachidori and Sakaemachidori, Chuo Ward, Kobe City) and Nagasaki Chinatown [Nagasaki Shinchi Chukagai 長崎新 地中華街] (Shinchimachi, Nagasaki City) (Figure 1). Of these, Yokohama Chinatown is the largest for its scale. At the end of 2002, the number of Chinese nationals residing in Yokohama City was 20,537, of whom 5,529 (26.9\%) reside in Naka Ward, where Yokohama Chinatown is located.

On the other hand, the number of Chinese nationals residing in Kobe City at the end of 2002 was 11,580 of whom 5,433 (46.9\%) reside in Chuo Ward, where Kobe Chinatown is located. At the end of 2002, the number of Chinese nationals residing in Nagasaki City was a mere 1,421. Compared with Yokohama Chinatown, Kobe and Nagasaki Chinatowns are smaller in scale and promotion as tourist spot was retarded. However, since the 1980s, they have experienced an outstanding development.

\section{Yokohama Chinatown [Yokohama Chukagai]}

\section{Formation of Chinatown and ethnic Chinese}

Right after the opening of the Port of Yokohama in 1859, American and European trading companies established trading houses in the foreign settlement, which was developed by reclaiming the sandbar in ex-Yokohama Village (Otobe 2002). The trading house of Jardine Matheson \& Co. from England, built on 1banchi [street number 1] in the settlement, was called "No. 1 English House." Many of these trading companies had already engaged in trade with China, based in Hong Kong, Guangzhou, and Shanghai. These Western mer- 


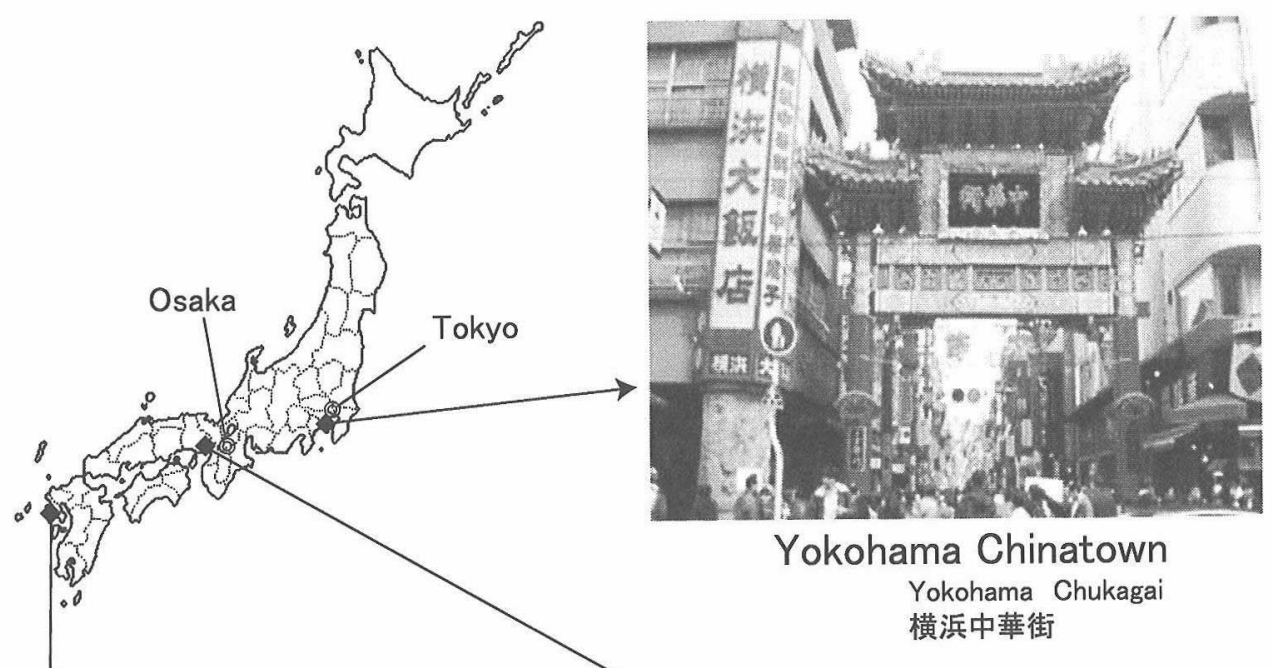

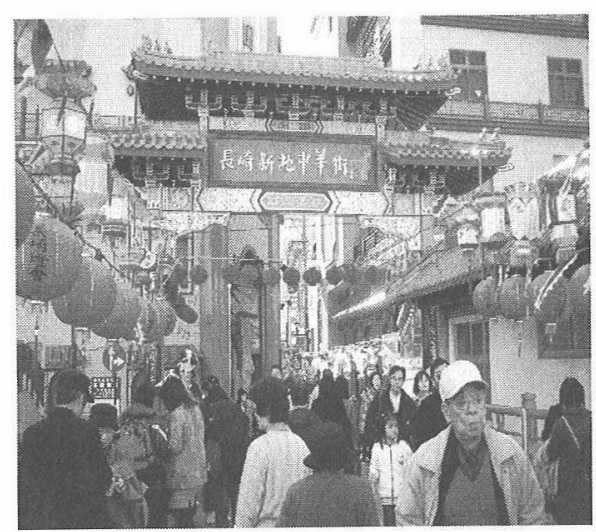

Nagasaki Chinatown

Nagasaki Shinchi Chukagai 長崎新地中華街

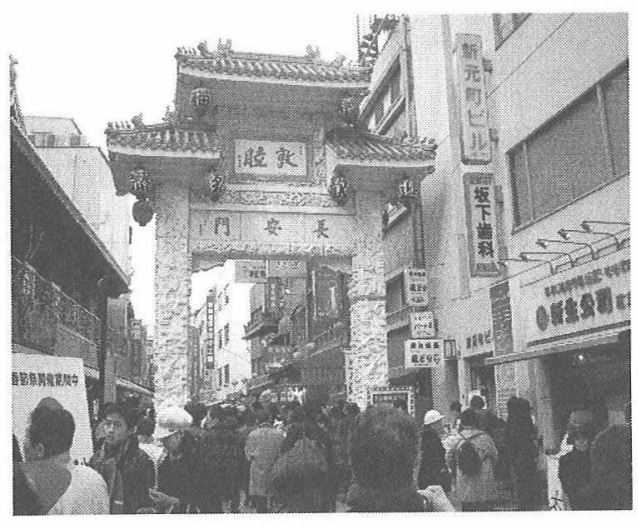

Kobe Chinatown

Kobe Nankinmachi 神戸南京町

Figure 1. Location of the Three Big Chinatowns in Japan.

chants expanded their operations into Yokohama, with accompanying Chinese as compradors because of their ample experience in the trade with China. ${ }^{1}$ In Yokohama too, Western merchants accompanied these Chinese compradors from Hong Kong and Shanghai, and entrusted them to negotiate with Japanese merchants in the buying of raw silk and tea, which used to be the main products imported from Japan in those days. Besides these compradors, the Westerners came to the Port of Yokohama accompanied by many Chinese: cooks and servants at home, carpenters, coolies at the harbor and so on. These Chinese would be the origin of the ethnic Chinese in Yokohama (Nishikawa and Ito 2002).

At that time, foreigners were compelled to live within the foreign settlement. After the conclusion of Ching-Japan Amity Treaty in 1871, the trade between China (then Empire of Ching) and Japan flourished. Chinese engaging in various professions came to reside in one concentrated area of the foreign settlement, and a Chinatown was gradually formed. Before World War II, Chinatowns were called Nankinmachi [南京街] or Shinamachi [支那街] by the Japanese. One of the outstanding characteristics of Chinatown in Japan is that it was formed in a city whose port was opened to foreigners at the end of Edo era. This can be said not only for 
Yokohama, but also for Kobe and Nagasaki.

Within the foreign settlement, the location where Yokohama Chinatown was formed used to be a damp lowland, as it was called "Reclaimed Settlement." Although the English, American and French established their trading houses near the port, they preferred to build their own residence in the dry highland settlement called Yamate [up the hill], where the Foreign General Cemetery and Harbor View Park are located today, on the hill behind Motomachi Shopping Street. That is, there existed residential segregation within the foreign settlement between the Westerners and the Chinese. Although residential conditions were inferior, the lowland was affordable for the Chinese. They came to reside there and concentrated to form a Chinatown (Yamashita 1991).

As to the homeland of the ethnic Chinese in Yokohama Chinatown, many have been from Province of Guangdong, such as Xiangshan 香 山 Prefecture (now Zhongshan 中山 City) located to the north of Macao and the birth place of Sun Yat-sen, and the Southern Delta of Zhu Jiang River, such as Gaoming 高明 Prefecture. ${ }^{2}$ According to the data in $1962,53 \%$ of the Chinese residing in Yamashitacho, where Yokohama Chinatown is located, were from the Province of Guangdong (Yamamura and Kawamura 1963).

As the Ching-Japan War broke out in 1894, many Chinese returned to China from Yokohama, and the Chinese population showed a sharp decrease temporarily. However, as the War came to an end in the following year, the Chinese population recovered at once to the pre-war level.

The scenic view of Chinatown in those days was as same as that in Mainland China: the main street was packed with two-storied stores made of red-brick, hanging billboards in Chinese letters, such as Chinese restaurants, exchange brokers and drug stores. Since it was the era of Ching dynasty in China, Chinese men in Yokohama also wore their hair in "pigtail" [竬髪]: they used to shave the head, with one tuft of long hair left, which hung down the back. Some Chinese women had their feet in chanzu 纏足, which used to be a Chinese custom to bend the toes of little girls to the sole and wrap tightly with cloth so that the toes would not grow. As men in those days felt that the unsteady steps of such women were attractive, chanzu used to be a symbol of beauty. The habit of smoking opium spread to Yokohama Chinatown, as well as to the cities of Mainland China and Chinatowns abroad. Around 1879, there used to be several opium "wholesale" stores in Chinatown. Gambling also thrived and accelerated, because the Japanese police could not regulate sufficiently the foreign settlement due to the extraterritoriality. Gambling and opium as well as prostitution were always problems.

As the number of Chinese men in the foreign settlement was overwhelming, there were many Japanese women who became mistresses of Chinese men. They were called Nankin Rashamen: Nankin 南京 means people from Nanjing, namely Chinese, and rashamen is an insulting word for Japanese women who became mistresses of foreigners, especially Westerners, during Meiji era.

As the foreign settlement was abolished in 1899, foreigners including Chinese were permitted to reside and engage in commerce outside the Foreign Settlement. On the other hand, more and more Japanese came to live and to open shops in the Chinatown.

\section{Destruction and reconstruction}

The Great Kanto Earthquake on September 1, 1923 brought destructive damage to Yokohama Chinatown. The Chinese population in Yokohama Chinatown at the end of August 1923, just before the Earthquake, was 4,705, of which the death toll was as many as 1,541, corresponding to almost one third. Even those who luckily survived the Earthquake left the destroyed and burnt Chinatown: some took refugee via the sea in Kobe, where many Chinese lived; others returned to China. It is also regrettable that traditional Chinese buildings and landscape of the Chinatown were lost. However, the reconstruction of Chinatown after the Earthquake was so rapid that it was restored to its former vigor and activity within several years.

The Great Air Raid of Yokohama in May 1945 destroyed Yokohama Chinatown again, 


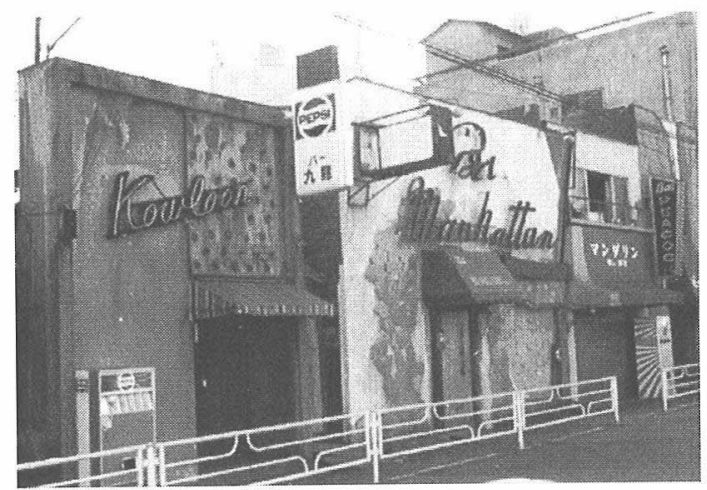

Photo 1. Bars for foreigners on Choan Road in Yokohama Chinatown in 1977.

but it achieved immediate reconstruction after World War II. Right after the War, Yokohama Chinatown was transformed into a black market shantytown and thrived temporarily. Then, due to the stationing of a number of U.S. troops in Japan, and the Korean War, which broke out in 1950, Yokohama Chinatown became an amusement area with an increasing number of bars, mainly for U.S. soldiers and foreign sailors. At the beginning of the 1970s, when I started to study Yokohama Chinatown, bars for foreigners were found remaining in places (Photo 1). This resembles the transition process of Kobe Chinatown to be mentioned later.

\section{Political conflict}

There are two Chinese schools in Yokohama today, and there are also two overseas Chinese associations. Both are separated politically into Mainland China supporters and Taiwan supporters.

The history of Chinese school in Yokohama began in 1897, when Sun Yat-sen and others founded Chusei School 中西学校. The political opposition within China after World War II had a serious influence on the education of Chinese children in Yokohama. In 1952, Yokohama Chinese School 横浜中華学校 was split into two by the opposition and conflict between Taiwan (Nationalist Party) supporters and Mainland China (Communist Party) supporters. This is the so-called "School Incident." For the same reason, Overseas Chinese Association was split into two. As the result, the Taiwan supporters stayed in the former school, whose name was

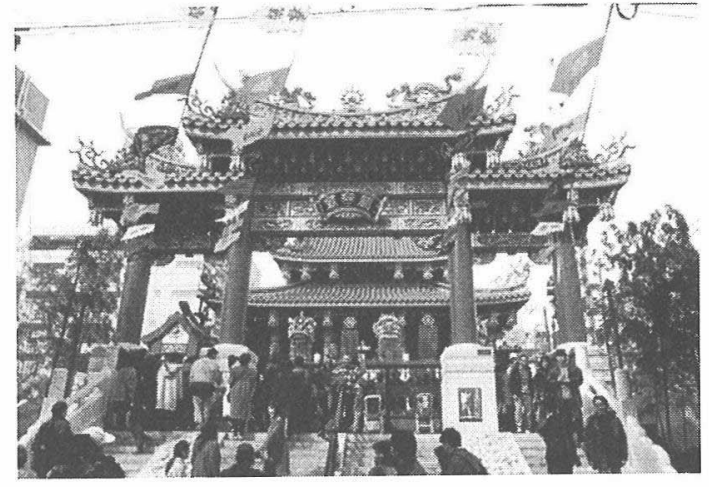

Photo 2. Reconstructed Kanteibyo in Yokohama Chinatown in 1996.

changed later to Yokohama Chuka Gakuin 横浜 中華学院, while the Mainland China supporters established a new school, Yokohama Yamate Chuka Gakkou 横浜山手中華学校 in 1953 at Yamate-cho, Naka Ward. These two schools exist to date.

The situation based on such political opposition does not usually come to the surface. However, the political standings of Yokohama Chinatown become clearer with every year at the beginning of October. First comes October 1st, the National Foundation Day 国慶節, when Mao Zedong declared the foundation of People's Republic of China on Tian'anmen Gate. Immediately follows October (10th month of the year) 10 th, which is called "Double-Ten 双十." On this date in 1911, Xinhai Revolution provoked the overthrow of the Ching dynasty. In the following year, in January 1912, the Republic of China was founded.

Reflecting respective political standing, each flag is hoisted upon Chinese restaurants, shops and organizations: on the National Foundation day, "Five-star red flag" of People's Republic of China; and on Double-Ten, "White sun in a blue sky flag" of Republic of China. There would be a splendid parade with resounding firecrackers; dragon dancers and lion dancers would march through the streets of Yokohama Chinatown.

August 14, 1990 was a very important day to commemorate in the long history of Yokohama Chinatown. On this day, Kanteibyo 関帝廟 [Emperor Guan Yu 関羽 Memorial], which had been seriously damaged by the fire on January 1, 1986, was reconstructed and a grand opening 
ceremony was held with more than 2,000 guests (Photo 2). This is when the ethnic Chinese in Yokohama Chinatown, of both Mainland China supporters and Taiwan supporters, conquered years of political opposition within their community. For the first time, ethnic Chinese of both groups cooperated to reconstruct the gorgeous and magnificent Kanteibyo, which became another sightseeing spot in Yokohama Chinatown.

People of both origins overcame the separation and opposition to organize the Construction Committee of Kanteibyo, and reconstructed it based on the donation of 445 million yen, with the total construction expenses of 580 million yen. This must precisely be the fruit of exercising the Chinese spirit of "Minor differences of opinion between us must be ironed out for our best common interests" ("Leave alone small differences, concur with big similarity 存小異, 求大同”).

Kanteibyo, the marvelous new symbol of Chinatown was reconstructed by inviting technical experts from Beijing and Taiwan with the best art of traditional Chinese construction. There had been a history of long political opposition in the Chinese community since the "School incident" in 1952. For those who know such history, it was almost incredible that the chief officers of both origins attended the ceremony together and offered congratulations on the opening of reconstructed Kanteibyo.

This became a clue to future cooperation. For example, at the events such as Chinese New Year 春節 and Emperor Guan Yu's Birthday 関 帝誕, it became the custom for ethnic Chinese of both groups to perform together on the same stage. Such cooperation beyond the difference of political standing serves more than anything to promote the development of Yokohama Chinatown.

\section{Promotion as a tourist spot}

As diplomatic relations between China and Japan were normalized in 1972, a China Boom arose all over Japan, and the number of people studying Chinese increased rapidly. Since the interest of Japanese people in Yokohama Chinatown was also heightened, more and more tourists were visiting the Chinatown. After the normalization of diplomatic relations, the products imported from Mainland China became affluent: the number of shops selling Chinese products, folklore products and Chinese cakes to tourists increased, not to mention the number of Chinese restaurants. ${ }^{3}$

On the other hand, for the improvement and development of Yokohama Chinatown, the Chinese and Japanese who own shops in Yokohama Chinatown cooperated to establish Yokohama Chinatown Development Association in 1971. This association has been trying to plan and organize a town full of Chinese atmosphere: it built pailou 牌楼 (Chinese-style decorated gate) at each entrance of Yokohama Chinatown; it hosts the Chinese New Year Festival; and it endeavors to make Yokohama Chinatown better known through the media, such as television, newspapers and magazines.

In the 1980s, a so-called "gourmet boom" and ethnic boom flourished in Japan, and Japanese interest in Chinese cuisine rose even more. Yokohama Chinatown, where Chinese restaurants are concentrated, has developed into a tourist spot visited by people not only from Yokohama and Tokyo Metropolitan area, but also from everywhere in Japan. Chartered large-size sightseeing buses, tourists in groups and students at school excursion would come to Chinatown.

It should be noted that since the 1980 s, students from Mainland China have increased in Yokohama Chinatown. As the shops and restaurants in Yokohama Chinatown were always understaffed, many students from Mainland China working as staff in Chinese restaurants and Chinese product shops became outstanding from the 1980s. The chance to hear native Chinese and halting Japanese increased, adding even more Chinese atmosphere to Yokohama Chinatown.

In January 1993, Council for the Planning of Yokohama Chinatown was organized by the 24 organizations relating to Chinatown, including Yokohama Chinatown Development Association and Yokohama Overseas Chinese Association. The Council promoted rebuilding and building of pailous, and its completion was commemorated in a grand ceremony in May 1995. 


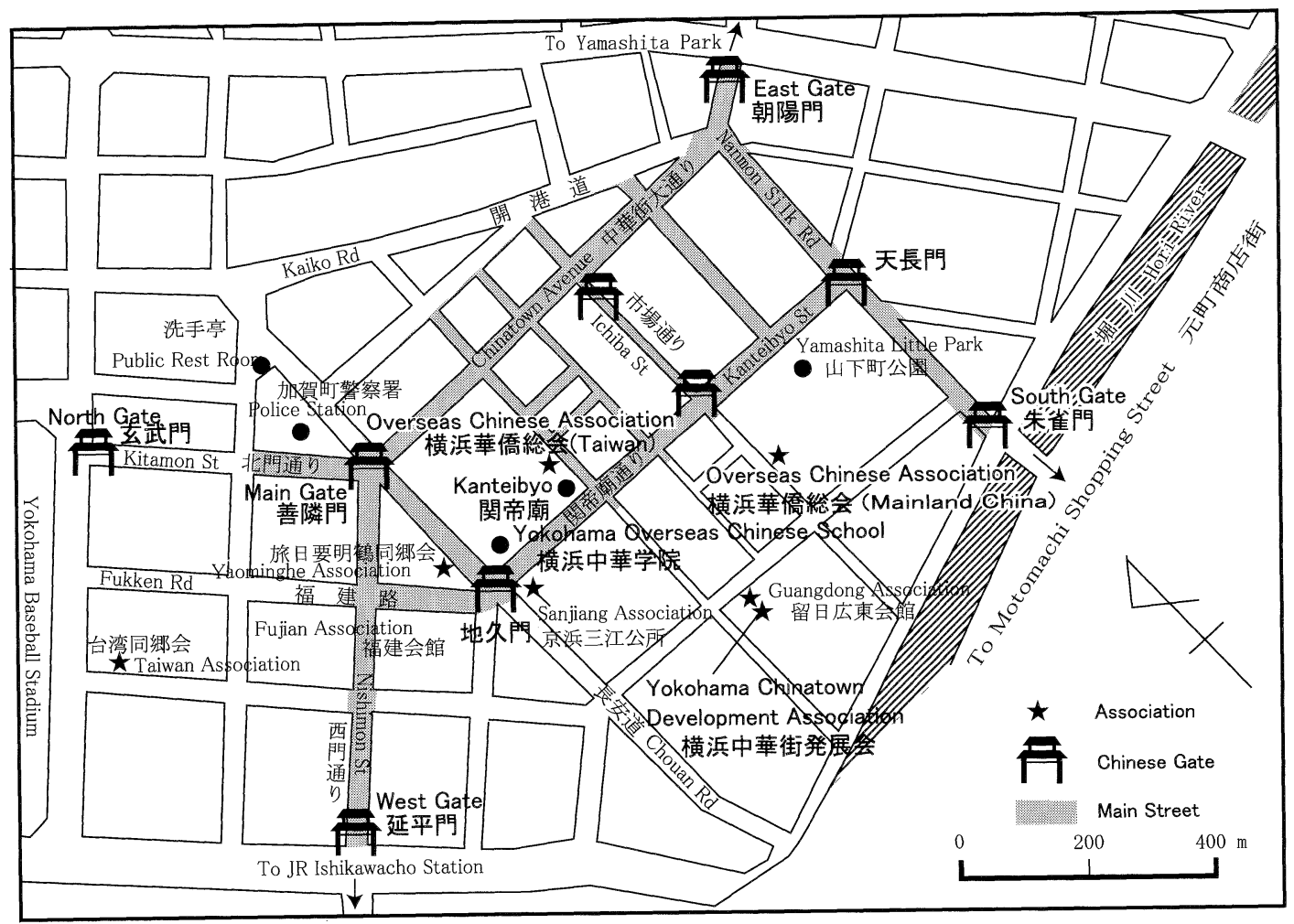

Figure 2. Yokohama Chinatown in 2003.

As the so-called "Bubble Economy" flourished from the mid-1980s, many shops (mainly Chinese restaurants) were rebuilt, extended or reconstructed into high-rise buildings all over Yokohama Chinatown. Until the Bubble Economy ended in 1990, Yokohama Chinatown thrived remarkably. It became the area that boasts the highest sales in the restaurant business in Kanagawa Prefecture. Shops with Japanese management increased, as well as those with Chinese management, and Yokohama Chinatown extended its coverage to the surrounding areas (Figure 2).

One of the important factors of such development was the advantageous location; Yokohama Chinatown is adjacent to the central business district. Many influential organizations, such as Kanagawa Prefecture Government and Yokohama City Hall, are located in the area surrounding Yokohama Chinatown. Invitation to various receptions and dinners used to be an important source of income for every shop in Yokohama Chinatown. However, since around 1995, "receptions for governmental officials by government officials" came to be criticized, and many local governments cut down their reception budgets. Although Yokohama Chinatown seems to have developed without any problems, with the end of the Bubble Economy and the cutting of reception budgets, it faced a turning point. Even famous long established Chinese restaurants are striving to survive, by setting up courses at low price and starting "all you can eat" buffet style. ${ }^{4}$

\section{Kobe Chinatown [Kobe Nankinmachi]}

\section{Formation of Chinatown}

The Port of Kobe was opened in January, 1868, falling behind Ports of Yokohama, Nagasaki and Hakodate, which were opened in 1859. Right after the opening, Western merchants came to start business and Chinese came as their cooks and servants. Some Chinese came under the name of employees of Westerners, but were actually engaged in smuggling. Others immigrated from Nagasaki and Yoko- 
hama, whose ports were already opened. As to their origin, most were from Guandong Province, followed by those from Sanjiang 三江 Region (three southeastern provinces of Jiangsu, Zhejiang, and Jiangxi; including Shanghai), then Fujian Province.

Before the conclusion of Ching-Japan Amity Treaty in 1871, Chinese used to be a national without treaty. As a result, many Chinese came to the Port of Kobe as employees of foreigners from U.S. and Europe, which had already concluded treaty with Japan. It was regulated that a Chinese, a national without treaty, should not live in the foreign settlement. They had to reside in so-called "mixed residing area," adjacent to the foreign settlement. Since the foreign settlement in Kobe was not completely constructed and was too small, the Japanese government had no other measure than to permit foreigners to live together with Japanese in the "mixed residing area 雑居地" (Chuka Kaikan 2000: 32-33). Around 1877, the ethnic Chinese started to reside around today's Nankinmachi.

From the opening of the Port to the revision of the Treaty in 1899, the Chinese community in Kobe was developed on the initiative of leading merchants. Many of them resided in and around present-day Nankinmachi.

As the Treaty was revised, extraterritoriality was abolished and foreigners were permitted to live mixed with Japanese. Ethnic Chinese were permitted to engage in other professions than trade in every location in Japan: they started so-called san ba to gyo 三把刀業 (three blade businesses, professions using three kinds of blade, that is, knife for Chinese cuisine, scissors for tailor, and razor for barber) and miscellaneous business such as kimono [traditional Japanese clothing] fabric peddling. After the revision of the Treaty, the population of Ethnic Chinese residing in Kobe increased, which means that Chinese business operations were expanded into miscellaneous businesses. In 1930, the number of Chinese residents in Kobe increased to 6,636, because the Japanese economy flourished after World War I, and also because those suffering from damage in the 1923 Great Kanto Earthquake moved from Yokohama to Kobe.

Before World War II, Kobe Chinatown was so

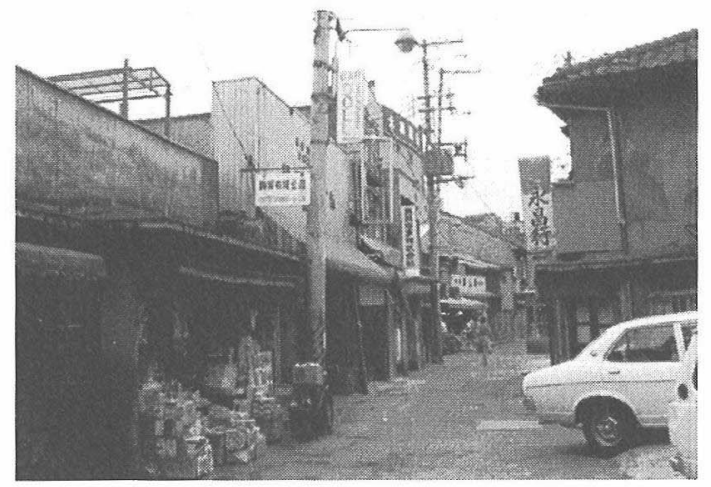

Photo 3. Main street, present Nankin East Road, of Kobe Chinatown in 1977.

prosperous that it was famous not only within the local district, but also in Kinki region [Osaka and Kyoto metropolitan area and surrounding prefectures]. Kobe Chinatown had the characteristics of a food market where Japanese stall keepers joined, as well as of a Chinatown.

As the Manchurian Incident broke out in 1931 and the Japanese-Chinese War began in 1937, more and more Chinese returned to China. Since China and Japan entered into a serious state of war, ethnic Chinese were treated as an "enemy nation" and their activities became strictly restricted. The worsened relations between China and Japan were reflected most obviously in trade. Furthermore, the intensifying movement in Southeast Asia to boycott Japanese products caused Chinese merchants' trading operations to stagnate.

The air raid in 1945 transformed the center of Kobe City including Nankin-machi into a burnt field. It is said that the restoration of Kobe after the War was started in the black market. As Japan was defeated in the war, Chinese and Korean, who became "victor nations," played an important role in the black market.

\section{The redevelopment of Chinatown}

When discussing the promotion process of Kobe Chinatown as a tourist spot, there are many similarities with Yokohama Chinatown, although the timing is not exactly matched.

Right after the end of World War II, as the U.S. Army came to be stationed in Japan, many bars were built for U.S. soldiers around Kobe 


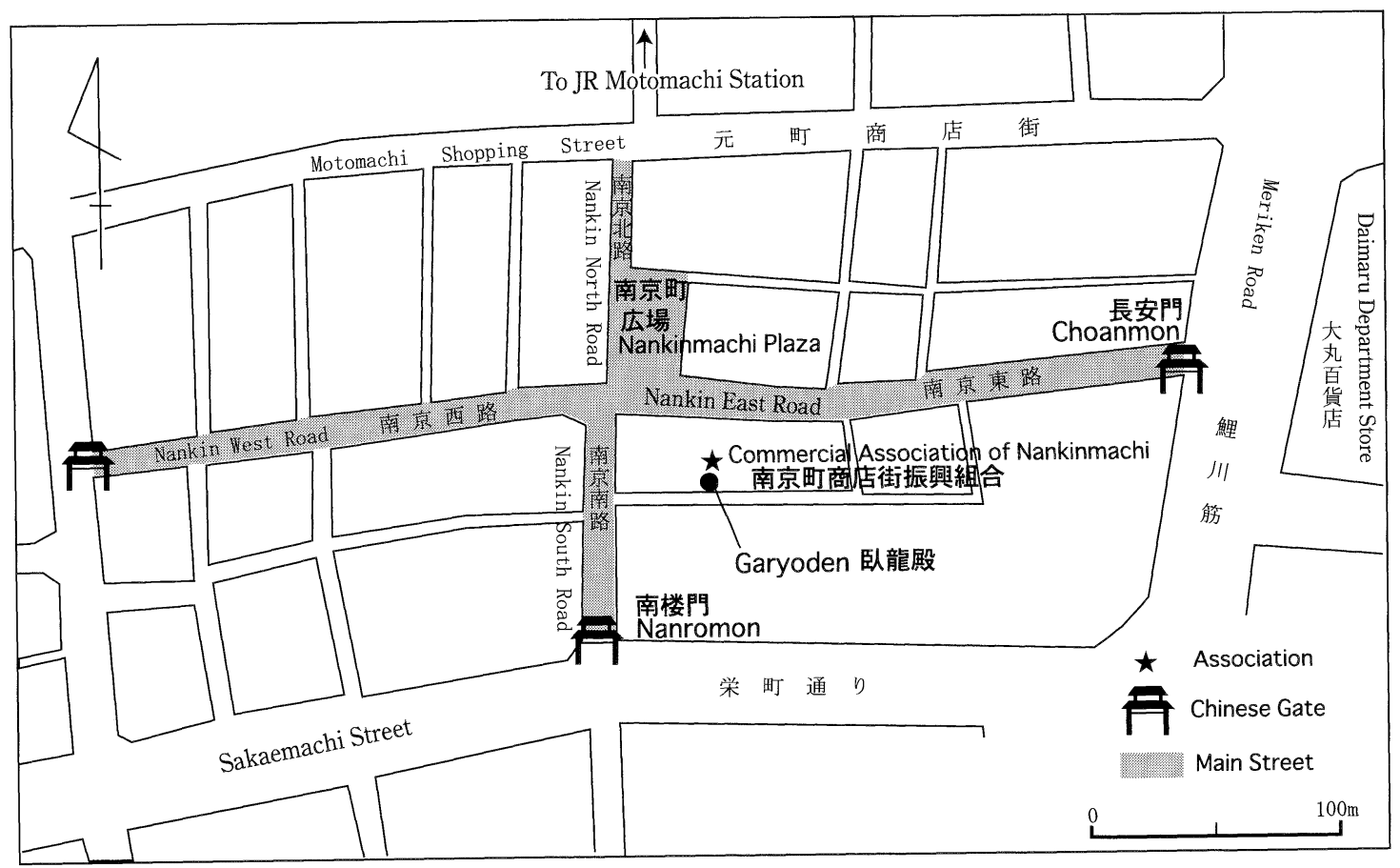

Figure 3. Kobe Chinatown in 2003.

Chinatown, and it became an amusement area. In common to Yokohama Chinatown, Kobe Chinatown used to have a characteristic as an amusement area for foreigners before it was promoted as a tourist spot.

It may be said that the promotion of Kobe Chinatown as a tourist spot commenced with a redevelopment plan based on the collaboration between Nankinmachi Development Association 南京町商店街振興組合 organized in 1977 and the district improvement plan by Kobe City (Photo 3). In 1981, "Reconstruction and Environmental Improvement Plan for Nankinmachi" was established by Kobe City. According to the Plan, the main street of 160 meters from east to west, and another of 110 meters from north to south, both 8 meters wide, would be constructed; Nankinmachi Plaza would be constructed in the center with a Chinese style pavilion and Chinese gates, the symbol of Kobe Chinatown. In 1982, Nanromon 南楼門 was built at the entrance of Kobe Chinatown as the first Chinese gate (two gates were added later), and in 1985, Choanmon 長安門 was built. In 1993, three-storied Chinese style building (public rest rooms and a community hall inside) named Garyoden 臥龍殿 [Lying Dragon Palace] was constructed as a new tourist spot of Kobe Chinatown (Figure 3).

In 1987, Nankinmachi Shunsetsusai 南京町春 節祭 [Chinese New Year Festival] began to be celebrated, sponsored by the Nankinmachi Development Association, with the intention to publicize Kobe Chinatown as a tourist spot. Today, this is the biggest annual event in Kobe Chinatown (Photo 4). The Shunsetsusai in 2003 was visited by as many as 410,000 people during three days.

As of 2003, members of the Nankinmachi Development Association was 100, out of which less than one third are Chinese. Although there are mainly Chinese restaurants and Chinese grocery and general merchandise stores (such as Chinese tea and Chinese products) in Kobe Chinatown, the number of Chinese restaurants is 25, not as many as in Yokohama Chinatown. There are many Chinese restaurants that serve discount-priced lunch menu such as those in Yokohama Chinatown, and many office workers come to take lunch from surrounding business districts. Among these Chinese restaurants, many hang up billboards of "Guangdong Cuisine" or "Guangdong Restaurant." This means that Kobe Chinatown is composed 


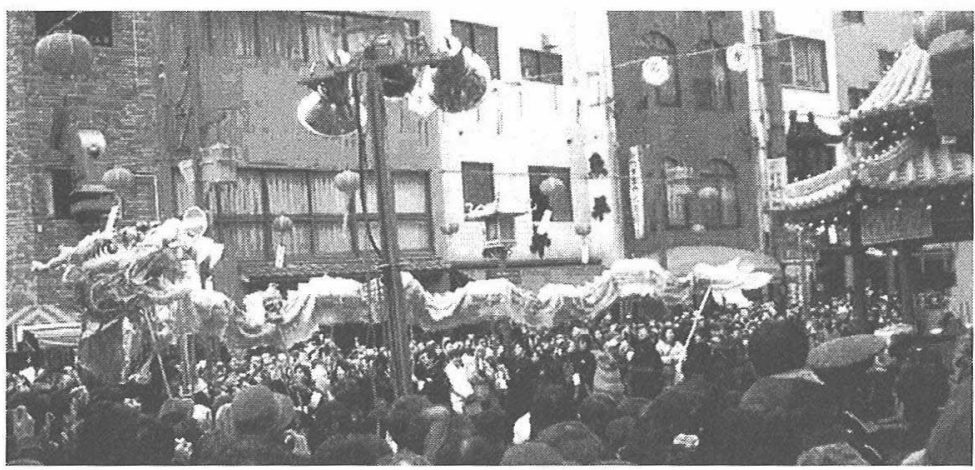

Photo 4. Dragon Dance in Shunsetsusai, Chinese New Year Festival, in Kobe Chinatown in 2003.

mainly of Chinese from Guangdong Province.

Early in the morning on January 17, 1995, however, the Great Hanshin-Awaji Earthquake (Southern Hyogo Prefecture Earthquake; death toll of more than 6,300) violently struck Nankinmachi, which had been developing steadily.

The damage to Kobe Chinatown was death of one part-time employee and eight completely destroyed buildings. This was relatively less serious than within Kobe, which suffered incredible damage. ${ }^{5}$ The Chinatown was half destroyed and the Ancient Chinese Terracotta Worriers and Horses 兵馬俑 displayed on the street were cruelly destroyed, with their necks and bodies broken. Although people were taking time and effort to prepare for Shunsetsusai to be celebrated in February, there was no alternative but to cancel. In 1995, Shunsetsusai came on January 31st. On this day, the Nankinmachi Development Association served boiled dumplings, noodle soup, croquettes, Shaoxing wine 紹興酒, etc. free of charge in Nankinmachi Plaza. Such hot meal greatly pleased those suffering from the damage of Earthquake. This encouraging news of rapid restoration of Nankinmachi was reported via media all over Japan.

However, the effect of the Great Earthquake lingered and the number of tourists visiting Kobe Chinatown decreased substantially. This is because the number of those visiting Kobe itself decreased dramatically. However, Kobe City and the citizens are cooperating in the new planning for Kobe Chinatown, full of Chinese atmosphere with colored street pavement, without utility poles by laying cables under the ground.

\section{Nagasaki Chinatown [Nagasaki Shinchi Chukagai]}

\section{Formation of Chinese Quarter and Chinatown}

Nagasaki used to be the only trading port in Japan during the era of seclusion policy. The trading operations of Chinese were limited within Nagasaki and they were compelled to live in the Chinese Quarter 唐人屋敷 $(31,000$ square meters $=7.66$ acres), only where they were permitted to engage in trade.

China and the Netherlands were the only trading partners at Nagasaki during the era of the seclusion policy. Japan was importing mainly raw silk, silk textiles, cotton, cotton textiles, medicine, ginseng and sugar; and exporting mainly silver, copper, gold and seafood products.

Since it was difficult to regulate smugglers, the Shogunate restricted the arrival into the Port and established the Chinese Quarter in 1689, where only Chinese were permitted to live. Chinese merchants resided within the Chinese Quarter, where trading negotiations took place. Any persons other than officials and merchants with special permission and courtesans of Maruyama District were strictly prohibited from entering the Chinese Quarter. Dojindo Shrine 土神堂 (dedicated to Fukutoku Seishin 福 徳正神 [God of Earth and Fertility]), Kan'nondo Shrine 観音堂, Tenkodo Shrine 天后堂 and Fukken Kaikan 福建会館 (Assembly Hall for People from Fujian) remain today in the area that used to be the Chinese Quarter. Chinese merchants who came to Nagasaki built a Chinese-style temple for respective groups of the same origin. 


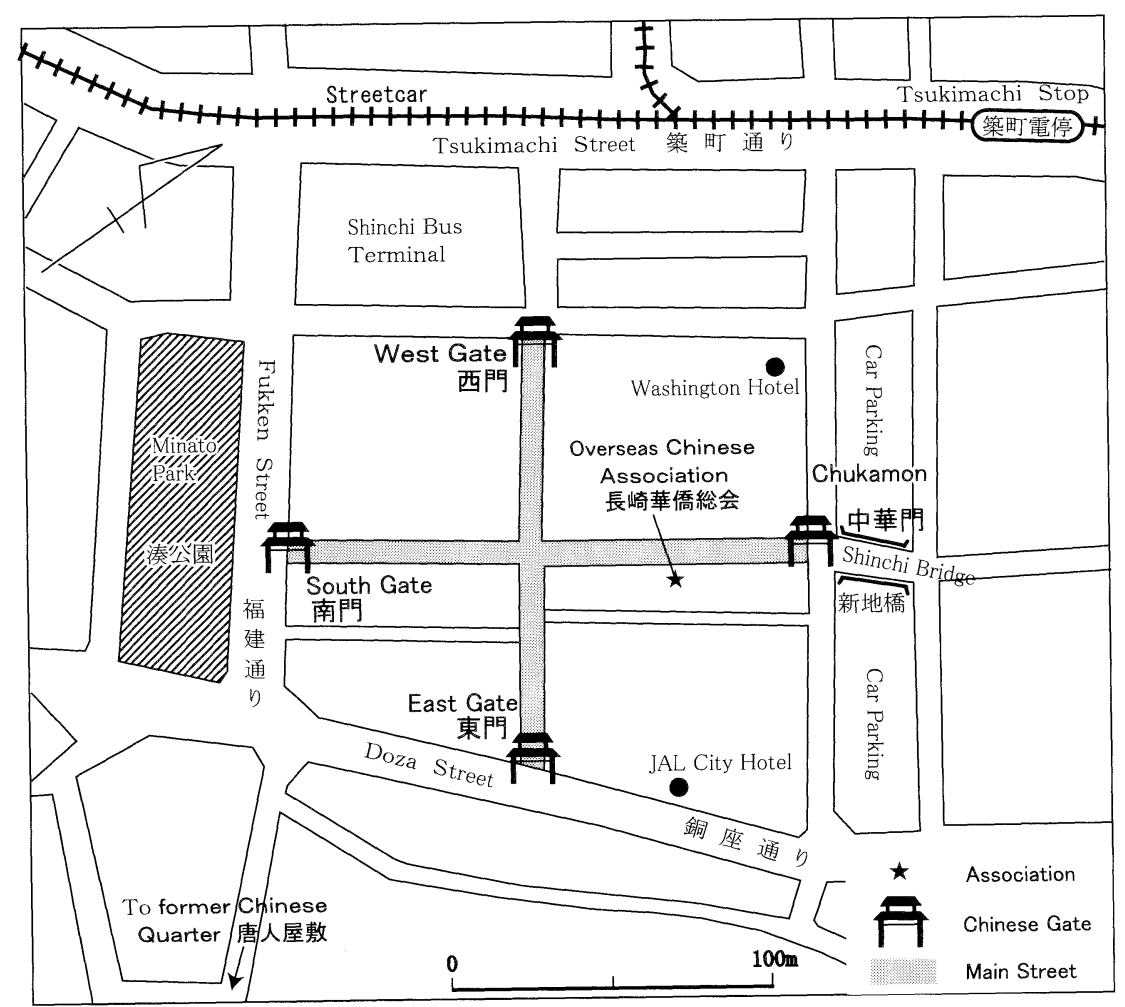

Figure 4. Nagasaki Chinatown in 2003.

They are called Four Chinese Temples 唐四箇 寺: Sofukuji Temple (built by people from Fuqing), Koufukuji Temple (built by people from Sanjiang Region), Fukusaiji Temple (built by people from Ming'nan [southern Fujian Province]), and Shoufukuji Temple (built by people from Fujian, and later managed by people from Guangdong).

Nagasaki Chinatown today originates from the island constructed in 1702 by reclaiming the sea. As there were Japanese-style storehouses in this artificial island to store freights transported by trading ships called "Tousen" [Chinese ships] arriving from China to the Port of Nagasaki, it was named Shinchi Kurasho 新 地蔵所 [warehouse place in the new land]. After the opening of the Port of Nagasaki just before the Meiji Restoration of 1868, the ethnic Chinese left the Chinese Quarter and started to concentrate their residences in Shinchi Kurasho, which became a Chinese settlement and developed into today's Nagasaki Chinatown.

One of the outstanding characteristics of the Chinese community in Nagasaki is that there are so many people and their descendants from Fuqing 福清 Region, which is located in the north of Fujian Province, near Fuzhou. Nagasaki served as a base for people from Fuqing to disembark on Japan. The traditional profession of people in Fuqing was peddling of cloth for kimono, and they spread all over Japan, from Hokkaido to Kyushu (Abe 1997).

\section{Promotion of Chinatown as a tourist spot}

The area called Nagasaki Chinatown today used to be a town where many merchants gathered before World War II. Many of these merchants were hanging up billboards with the company name of “- -go 号." At that time, the area was neither called Shinamachi 支那街 (Chinatown) nor Nankinmachi 南京町, but just Shinchi 新地. There used to be many buildings of Chinese merchants, made of red bricks, but they were lost in a big fire in 1947.

Compared with Yokohama Chinatown and Kobe Chinatown, promotion of Nagasaki Chinatown as a tourist spot was started late. In 1984, Nagasaki Shinchi Chukagai Development Asso- 


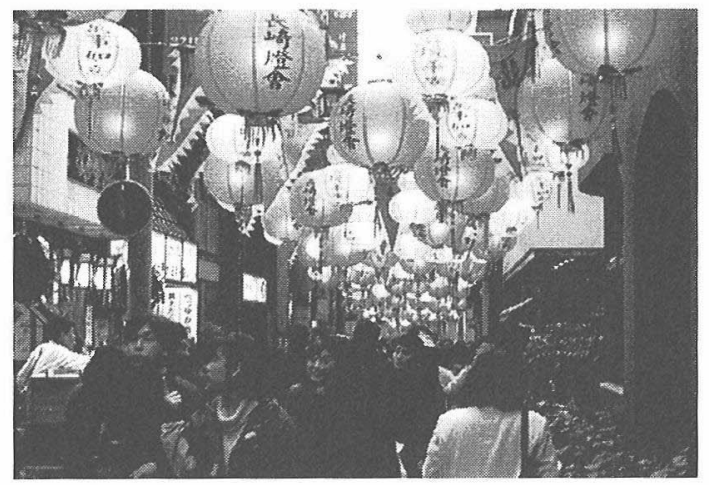

Photo 5. Lantern Festival in Nagasaki Chinatown in 2003.

ciation 長崎新地中華街商店街振興組合 was established and the improvement of Nagasaki Chinatown began. As of 2003, members of the Association were 40 , of which Chinese and Japanese were almost half and half. Most of the ethnic Chinese residing in Nagasaki Chinatown are from Fuqing City, Fujiang Province and its adjacent area, and their descendants of the second and third generations.

In 1986, the stone pavement of streets was completed and Chinese gates were built, being finished by craftsmen invited from Fuzhou, sister city of Nagasaki City. Later, Chinese gates painted in vermilion were built at all four entrances, north, south, east, and west, of $\mathrm{Na}$ gasaki Chinatown. Each gate was adorned with a symbolic animal from Chinese legend that represents direction: Seiryu [Blue Dragon] on East Gate, Byakko [White Tiger] on West Gate, Suzaku [Vermilion Phoenix] on South Gate and Genbu [Snake and Turtle] on North Gate. Moreover in 1988, Shinchi Bridge, which had been made from concrete, was rebuilt into a Chinese style bridge painted in vermilion (Figure 4).

With the construction of pailou in 1987, Shinchi Chinatown Lantern Festival started to be celebrated every year from January 1 st to 5 th of the ancient Chinese calendar. This festival intends to increase the number of tourists visiting Nagasaki Chinatown, which had been less famous at a nationwide level than Yokohama Chinatown and Kobe Chinatown. Since 1994, Executive Committee for Nagasaki Lantern Festival has been organized in cooperation with Nagasaki City (Tourist Bureau, Nagasaki City

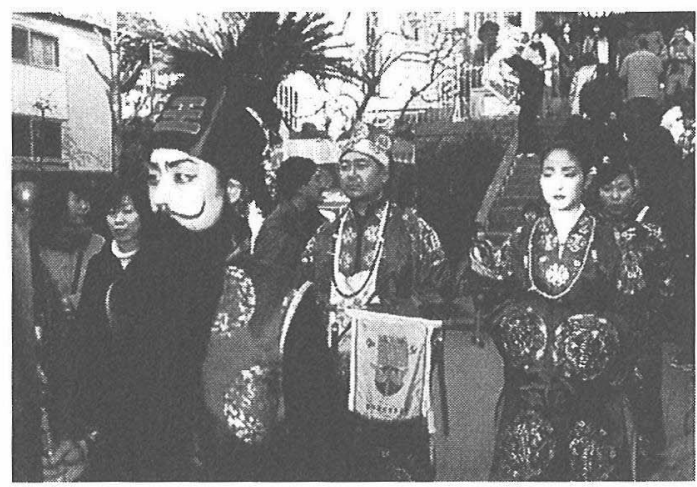

Photo 6. Maso Parade during the Lantern Festival in former Chinese Quarter near Nagasaki Chinatown in 2003.

Hall). Thus Nagasaki Lantern Festival 長崎燈会 has been celebrated on a larger scale as "a big event in Nagasaki" during winter, the off peak season for tourists (Wang 2001). The duration was also extended to 15 days, from January 1st to 15 th of ancient calendar. In 2003, the Festival was celebrated from February 1 st to 15 th, being visited by as many as 800,000 tourists (Photo 5).

More than 12,000 Chinese-style lanterns decorate Shinchi Chinatown and Minato Park, the main site, converting them into a world of fantasy and illusion. During the festival, Maso Parade 媽祖行列 ${ }^{6}$ and Emperor Parade ${ }^{7}$ march through not only the streets around the Chinatown, but also the shopping district and the former Chinese Quarter (Photo 6).

Since the Lantern Festival has been introduced as a big event by television, radio, newspapers and magazines, this new attempt has become a great success for the tourism in $\mathrm{Na}$ gasaki during winter. In this way, Nagasaki Chinatown has also become better known nationwide in Japan.

With the promotion and development as a tourist spot, the number of shops that serve Chinese dim sum (such as Chinese buns and cakes) and souvenir shops (such as Chinese products, grocery and general merchandise stores) has been increasing, not to mention Chinese restaurants. These days, many of these shops are newly built or rebuilt. Since such buildings tend to adopt design with more Chinese atmosphere, the town has been planned and developed in consideration of the landscape 
as Chinatown.

\section{Conclusion: Regional Characteristics of Chinatowns in Japan}

Within Japan, Chinatowns have been formed in three cities (i.e. Yokohama, Kobe and Nagasaki) and are named respectively Yokohama Chinatown, Kobe Chinatown, and Nagasaki Chinatown. Of these, Yokohama Chinatown is the largest for its scale. Yokohama Chinatown has developed with cooperation beyond the difference of political standing of the ethnic Chinese. Kobe Chinatown was commenced with the redevelopment plan based on the collaboration between Nankinmachi Development Association and the district improvement plan by Kobe City. Nagasaki Chinatown has become better known nationwide in Japan with promotion and development as a tourist spot since the Lantern Festival has taken place.

As discussed above, every Chinatown in Japan exists as an important tourist spot in its local city, as well as an area in which Chinese restaurants are concentrated. This is the most remarkable regional characteristic of Chinatowns in Japan, from the global point of view (Yamashita 1999). Compared with those in Southeast Asia, Europe and the U.S., it is outstanding that Japanese customers and tourists are more important than ethnic Chinese for the functions of Chinatowns in Japan. Many Chinatowns in foreign countries such as San Francisco, New York, and Vancouver, are important tourist spots. However, there are many apartments and houses for Chinese residents and Chinatowns provide various services of daily life to Chinese residents.

Another remarkable characteristic of ethnic Chinese in Japan is that they have been adapting themselves to Japanese community by promoting Chinatowns as tourist spots and by positively utilizing the tradition of Chinese culture, especially food culture, as a tourist resource. Chinatown in Japan is a town that embodies the image of China, cherished by so many Japanese.

In Japan, Chinatown has been developed as a tourist spot. This is based upon the interest in, and preference for, Chinese culture among the
Japanese people.

With the promotion as tourist spots, the landscape of Three Big Chinatowns in Japan is intensifying its Chinese character, when observed from the outside. On the other hand, the ethnic Chinese are losing their traditional lifestyle from within. Furthermore, their residence and business scene tend to be separated recently. Although their shops are located in Chinatown, more and more ethnic Chinese are to live outside Chinatown. This means that the Chinese population is increasingly leaving the center, as is observed in Chinatowns of Europe and the U.S.

In the future, we should pay attention to the formation of new Chinatowns by the new immigrants from Mainland China, whose number increased sharply after the reformation and liberalization in China, especially from the mid1980s.

\section{Acknowledgments}

I express my gratitude to Chinese people and Chinese associations in Yokohama, Kobe, and Nagasaki for cooperation in my research. Part of this study was supported by the Grant-in-Aid for Scientific Research by the Japan Society for the Promotion of Science (2002-2004), No. 14580092, headed by Yamashita Kiyomi.

(Submitted 16 April 2003) (Accepted 4 August 2003)

\section{Notes}

1. "Comprador" system was started in China by English merchants to negotiate in their favor. They employed Chinese merchants exclusively for their trading company and entrusted them with buying in the Chinese market the products to be exported.

2. On the Chouan Road of Yokohama Chinatown, there is a building of Japan Association of Chinese from Prefectures of Gaoyao 高要, Gaoming 高明, Heshan 鶴山 in Guangdong Province [旅日要明鶴同郷会], an organization of people from the same homeland.

3. According to my field study in 1976 , there were 199 shops (only those managed by Ethnic Chinese) in Yokohama Chinatown, of which 95 were Chinese restaurants, 25 were bars, saloons and coffee shops, 20 were Chinese grocery and general merchandise stores, 15 were Chinese cake shops and bakeries, and 15 were Chinese product and folklore product stores (Yamashita 
1979).

4. According to my study in July 1996, there were as much as 196 Chinese restaurants in Yokohama Chinatown. There were also 78 bars, saloons and coffee shops, 48 Chinese grocery and general merchandise stores, 26 Chinese product and folklore product stores, and 15 Chinese cake shops and bakeries (Yamashita and Students of Department of Geography, University of Akita 1997).

5. The number of Chinese killed in the Earthquake was as many as 48 including 16 students from China (Yasui, Chen and Guo 1996:250251).

6. Maso Parade is the reproduction of a parade during Edo era: when a Chinese ship arrived in the Port of Nagasaki, sailors used to carry the image of Maso [Goddess of safe navigation] to dedicate in the Chinese temple within the City.

7. Emperor Parade is the creation of the scene when the Emperor of China marched in the town on Chinese New Year's Day.

\section{References}

Abe Y. 1997. Nagasaki ni okeru zainichi chugokujin no shugyou jokyou no henka to kyojuchi ido [The changing occupation and residential mobility of Chinese in Nagasaki]. Jinbun Chiri [The Human Geography] 49: 395-411. (JE)

Anderson, K. J. 1991. Vancouver's Chinatown: Racial discourse in Canada, 1875-1980. Montreal: McGill-Queen's University Press.

Chuka Kaikan ed. 2000. Rakuchi seikon: Kobe kakyo to hanshin chuka kaikan no hyakunen [Roots in a new homeland: A hundred years of Chinese in Kobe-Osaka and their association]. Tokyo: Kenbun Shuppan.(J)

Lai, D. C. 1988. Chinatowns: Towns within cities in Canada. Vancouver: University of British Columbia Press.

Ma, L. J. C., and Cartier, L. eds. 2003. The Chinese diaspora: Space, place, mobility, and identity. Lanham: Rowman \& Littlefield Publishers.

Murphey, R. 1952. Boston's Chinatown. Economic Geography 28: 244-255.

Nishikawa T., and Ito I. 2002. Kaikoku nihon to Yokohama chukagai [The opening coutry of Japan and Yokohama Chinatown]. Tokyo: Taishukan Shoten. $(\mathrm{J})$

Otobe J. 2002. Jukyu seiki matsu no yokohama gaikokujin kyoryuchi no keikan [Landscape of Yokohama's foreign settlement at the end of the nineteenth century]. Rekishi Chirigaku [The Historical Geography] 44(5): 22-37. (JE)

Wang, W. 2001. Nihon kakyo ni okeru dento no saihen to esunishithi [Reorganization of tradition and ethnicity of Chinese in Japan]. Tokyo: Fukyousha. (J)

Yamamura S., and Kawamura T. 1963. Yokohama chukagai zairyu kakyou no tokushitsu ni kansuru jakkan no kosatsu, sono ichi. [A study of consideration on characteristics of Chinese in Yokohama Chinatown]. Yokohama Kokuritsudaigaku Jinbun Kiyo 9: 1-40.

Yamashita K. 1979. Yokohama Chukagai zairyu chugokujin no seikatsu youshiki [A study on Chinese way of life in Yokohama's Chinatown]. Jinbun Chiri [The Human Geography] 31: 321-338. (JE)

Yamashita K. 1986. The residential segregation of Chinese dialect groups in Singapore: with focus on the period before ca.1970. Geographical Review of Japan 59B: 83-102.

Yamashita K. 1987a. Breakdown of the residential segregation of Chinese dialect groups in Singapore. Science Report of the Institute of Geoscience, University of Tsukuba, Section A 8: 129-146.

Yamashita K. 1987b. Tonan ajia no chainataun [Chinatowns in Southeast Asia]. Tokyo: Kokonshoin.(J)

Yamashita K. 1988. Shingaporu no kajin shakai [Chinese community in Singapore]. Tokyo: Taimeido. (J)

Yamashita K. 1991. Yokohama chukagai to kakyo shakai: kaikou kara dainiji sekaitaisen made [Yokohama Chinatown and overseas Chinese community: from open of Yokohama Port to World War II ]. In Shutoken no kukan kozo [Spatial organization of Metoropolitan Area], ed. S. Yamamoto, 211-220. Tokyo: Ninomiya Shoten. (J)

Yamashita K. 1999. Riben tangrenjie zhi guanguang diquhua de jinzhan [Promotion of tourism of Chinatown in Japan]. In Wanxiang ershi yi ji haiwai huaren shimin shehui zhi bienxuan yu fazhan [The change and development of Chinese community for the 21st century], ed. H. Chen. Taipei: Association of Study for Chinese Overseas of Republic of China. (C)

Yamashita K. 2000. Chainataun: Sekai ni Hirogaru Kajin Nettowaku [Chinatowns: A Global Network of Ethnic Chinese]. Tokyo: Maruzen. (J)

Yamashita K. 2002. Tonan ajia kajin shakai to chugoku kyokyo: kajin, chainataun no jinbunchirigakuteki kousatsu [Chinese communities in Southeast Asia and emigrant homelands in China: An human geographical study on the ethnic Chinese and Chinatowns]. Tokyo: Kokon-Shoin. (J)

Yamashita K. and Students of Department of Geography, University of Akita, 1997. Yokohama chukagai to okubo esunikku taun: nihon ni okeru shinkyu hutatsu no esunikku taun [Yokohama Chinatown and Okubo Ethnictown: Two types of old and new ethnictowns in Japan], Shudai Chiri [Geographical Journal of Akita University] 44: 5768. $(\mathrm{J})$

Yasui S., Chen, L., and Guo, F. 1996. Hanshin daishinsai to kakyo [The Great Hanshin Earthquake of 1995 and the overseas Chinese in Japan]. Kobe: Kobe Shoka University and Kobe University. (J)

(C): written in Chinese

$(\mathrm{J})$ : written in Japanese

(JE): written in Japanese with English abstract 